\title{
Pulmonary function, smoking cessation and 30 year mortality in middle aged Finnish men
} Margit Pelkonen, Hannu Tukiainen, Markku Tervahauta, Irma-Leena Notkola,
Sirkka-Liisa Kivelä, Yrjö Salorinne, Aulikki Nissinen
University of Kuopio, Department of Public Health and General

Practice, Kuopio, Finland

M Pelkonen

M Tervahauta

I-L Notkola

A Nissinen

Kuopio University Hospital, Department of Pulmonary Diseases, Kuopio, Finland

M Pelkonen

$\mathrm{H}$ Tukiainen

University of Oulu, Department of Public

Health Science and

General Practice and

Oulu University

Hospital, Unit of

General Practice,

Finland

L Kivelä

Laakso Hospital, Helsinki, Finland

Y Salorinne

Correspondence to: Dr M Pelkonen, Univ. of Kuopio, Dept. of Public Health and General Practice, PO Box 1627, FIN-70211 Kuopio, Finland email: Margit.Pelkonen $a$ uku.fi

Received 15 November 1999 Returned to authors 31 January 2000 Revised version received 3 April 2000 Accepted for publication 25 April 2000

\begin{abstract}
Background-Although it is well known that impaired pulmonary function is a strong predictor of mortality and that smoking decreases pulmonary function, little is known about the long term effect of smoking cessation on mortality at different levels of pulmonary function. We have studied the impact of smoking cessation on mortality over the entire range of baseline pulmonary function.

Methods-The study subjects consisted of men aged 40-59 at entry who were the Finnish participants in the Seven Countries Study during 1959-89.

Results-In all the participants $(n=1582)$ impaired forced expiratory volume in $\mathbf{0 . 7 5}$ seconds $\left(\mathrm{FEV}_{0.75}\right)$ was significantly associated with increased all cause mortality. When those who gave up smoking during the follow up period were compared with continuous smokers $(n=860)$ all cause mortality was found to be decreased among those who quit. The relative adjusted hazard (HR) was 0.71 (95\% confidence interval 0.50 to 1.00 ). The median survival time in those who stopped smoking compared with those who continued to smoke from 1969 onwards was 7.65, 7.59, and 6.30 years longer in the lowest, middle and highest tertiles of adjusted $F E V_{0.75}$ distribution, respectively. In those who gave up smoking, mortality from cardiovascular causes was significantly lower (HR 0.60 (95\% CI 0.37 to 0.98$)$ ).

Conclusions-These findings suggest that smokers across the entire range of pulmonary function may increase their expectation of lifespan by giving up smoking.

(Thorax 2000;55:746-750)
\end{abstract}

Keywords: respiratory function; mortality; smoking cessation

Several population based longitudinal studies have shown impaired pulmonary function to be a strong predictor of increased mortality in both sexes. ${ }^{1-9}$ On the other hand, in many studies smoking has been found to be the major environmental factor in decreasing pulmonary function. ${ }^{10-12}$ Giving up smoking has not necessarily resulted in recovery of the level of pulmonary function but there may be slower rates of decline in pulmonary function..$^{70-13}$ However, little is known of the effect of smoking cessation on survival prospects over the entire range of initial pulmonary function. We have therefore assessed first the association of pulmonary function (forced expiratory volume in 0.75 second $\left(\mathrm{FEV}_{0.75}\right)$ ) with all cause mortality in a 30 year follow up of two general population cohorts of Finnish men. The benefit of smoking cessation on survival prospects over the entire range of baseline pulmonary function was then examined in those who gave up smoking during the study compared with those who continued to smoke. The cause specific mortality between those who gave up smoking and those who continued to smoke was also studied.

\section{Methods}

SUBJECTS

The original Finnish cohorts in the Seven Countries Study started in 1959 consisted of all men aged 40-59 years from two geographically defined rural areas, Ilomantsi $(n=823)$ in the east and Pöytyä and Mellilä $(n=888)$ in south-western Finland. ${ }^{14}$ Altogether 1675 (97.5\%) men were examined in 1959 according to the protocol of the Seven Countries Study. ${ }^{15}$ Re-examinations were performed in 1964, 1969, 1974, 1984, and 1989. In this study, when analysing the association between impaired pulmonary function and all cause mortality only those men $(n=1582)$ who had the complete baseline data needed for multivariate analysis were included. The influence of smoking cessation on mortality was studied by comparing those baseline smokers who quit smoking permanently during the course of the study with those who continued to smoke ( $\mathrm{n}=$ 860 at baseline).

The measurements of weight, height, blood pressure, and total cholesterol have been described elsewhere. ${ }^{15}$ Body mass index (BMI) was calculated as weight $(\mathrm{kg})$ divided by height $\left(\mathrm{m}^{2}\right)$. Smoking habits were recorded at the baseline and in subsequent re-examinations by a trained nurse according to a standard questionnaire developed for the Seven Countries Study. ${ }^{15}$ The questions concerned current and former smoking and the amount of smoking, which was asked by a five category question. For this study baseline smoking habits were classified into three categories: never smokers, past smokers in 1959 (had stopped smoking more than a year previously), and current smokers of cigarettes. At each examination those baseline smokers who had given up smoking up to that point were classified as quitters. The number of quitters and continuous smokers among surviving men was 72 and 788 in 1964, 142 and 609 in 1969, 227 and 379 in 1974, 205 and 120 in 1984, and 143 and 74 in 1989, respectively. During the whole 
period from 1959 to 1984 altogether 324 men shifted from continuous smokers to quitters.

All deaths between 1959 and 1989 were known. Death certificates were collected and causes of death coded using the Seven Countries Study protocol in which the official cause of death was used as the first line procedure but additional information, collected from personal doctors, hospitals, and other medical records, relatives, acquaintances, officials and any other witness of the fatal events, was used to verify the diagnosis. ${ }^{16}$ After the 15 th anniversary only review and coding of official death certificates were performed.

\section{LUNG FUNCTION}

During the 1950s $\mathrm{FEV}_{0.75}$ derived from spirometric tests was used as a measurement of pulmonary function (as a measure of obstruction). The same calibrated McKerrow spirometer was used in east and west Finland. Three forced expirations were performed and the best recording was taken as the $\mathrm{FEV}_{0.75}$. These values were corrected to BTPS and recorded in litres. To adjust the observed $\mathrm{FEV}_{0.75}$ values for variation in height and age, a linear regression model was fitted to the data of 225 men who had never smoked, had no symptoms of dyspnoea (history of shortness of breath while walking with other people of their own age or at their own pace on level ground), had no evidence of coronary heart disease (electrocardiographic evidence of old myocardial infarction - that is, a major Q wave on the ECG or a smaller $\mathrm{Q}$ wave with ST segment changes corresponding to Minnesota code items 1:1 or $1: 2$ and $5: 1-2,{ }^{17}$ a history of myocardial infarction verified in a hospital, or definite or probable angina pectoris assessed by a standard questionnaire ${ }^{15}$ ), nor prevalent respiratory disease. The presence of respiratory disease (physical or history of bronchial asthma, pulmonary emphysema, chronic bronchitis, pulmonary tuberculosis, bronchiectasis, pulmonary fibrosis and thorax deformity) was evaluated by the examining physician. The following equation was derived:

$\mathrm{FEV}_{0.75}=1.010 \times \mathrm{Ht}^{2}(\mathrm{~m})-0.028 \times$ age (years) +1.861

Age and height adjusted percentage predicted $\mathrm{FEV}_{0.75}$ values were calculated as percentage of observed $\mathrm{FEV}_{0.75}$ to predicted $\mathrm{FEV}_{0.75}$. Predicted values were based on the above mentioned regression equation. These adjusted values were classified into tertiles. Tertile limits for percentage predicted $\mathrm{FEV}_{0.75}$ values were $<88 \%, 88-102 \%$, and $>102 \%$.

STATISTICAL METHODS

Cox's proportional hazards regression model was used to analyse the relation between the tertile of $\mathrm{FEV}_{0.75}$ (\% predicted) and all cause mortality. ${ }^{18}$ The analysis was adjusted for potential confounders-namely, age, BMI, diastolic blood pressure, and total cholesterol added into the model as continuous variables and smoking habits classified into three categories (never smokers, past smokers, and current smokers).
The influence of smoking cessation on mortality was studied by a time dependent covariate describing the smoking status at each examination point from 1959 onwards. This covariate contained values which changed during the course of the study - that is, when men gave up smoking they shifted from continuous smokers to quitters. This analysis was adjusted for age, baseline $\mathrm{FEV}_{0.75}$ (\% predicted), BMI, diastolic blood pressure, and total cholesterol as continuous variables and the baseline amount of smoking as a dichotomous variable ( $<20$ and $\geqslant 20$ cigarettes/day). Mortality from cardiovascular disease (including heart disease, cerebral arterial and other arterial disease), cancer, respiratory diseases (including COPD, pneumonia, and other respiratory causes), and other causes were examined with a similar time dependent Cox's analysis. To examine whether the effect of smoking cessation was the same at all levels of pulmonary function, all time dependent Cox's analyses were repeated with an interaction term of smoking cessation and pulmonary function as an additional predictor. From these models only significant interactions are presented.

We illustrate the effects of smoking cessation on survival time in the long term at the different levels of $\mathrm{FEV}_{0.75}$ (\% predicted) with three figures based on Cox's regression models in which those baseline smokers who gave up smoking during 1959-69 are compared with those baseline smokers who continued to smoke. In these figures the year 1969 was chosen as the cut off point of quitting to ensure both a reasonable number of quitters and a reasonable length of follow up to estimate the effect of giving up smoking on survival time.

\section{Results}

The men in the lowest tertile of $\mathrm{FEV}_{0.75}$ (\% predicted) had a significantly increased risk of dying during the follow up period (table 1). The adjusted relative hazard (HR) was 1.56 (95\% confidence interval (CI) 1.35 to 1.81 ), $\mathrm{p}<0.001)$.

Among those men who smoked at the baseline, the effect of smoking cessation was studied by Cox's proportional hazards regression with smoking cessation as a time dependent covariate (table 2). The adjusted HR for all cause mortality was 0.71 (95\% CI 0.50 to $1.00, \mathrm{p}<0.05)$ among those who stopped smoking. Analysis of cause specific mortality revealed that those who gave up

Table 1 Multivariate adjusted hazard ratios * for all cause mortality during 1959-89 by tertile of $F E V_{0.75}+$ at baseline

\begin{tabular}{llll}
\hline & No of deaths & $\begin{array}{l}\text { Hazard ratio } \\
(95 \% \text { CI })\end{array}$ & p value \\
\hline Tertile of & & & \\
FEV $_{0.75}$ & 413 & $1.56(1.35$ to 1.81$)$ & $<0.001$ \\
Low & 343 & $1.08(0.93$ to 1.26$)$ & 0.295 \\
Middle & 330 & 1 & \\
High & 330
\end{tabular}

^From Cox's proportional hazards regression model adjusted for age, baseline smoking habits, body mass index, diastolic blood pressure, and total cholesterol. The highest tertile of $\mathrm{FEV}_{0.75}$ as a reference group.

†Percentage of predicted value from a study derived prediction equation. 
Table 2 Multivariate adjusted hazard ratios ${ }^{\star}$ for all cause and cause specific mortality during 1964-89 among those who quit between 1959-84 compared with continuous smokers

\begin{tabular}{|c|c|c|c|c|}
\hline \multirow[t]{2}{*}{ Cause of death } & \multicolumn{2}{|l|}{ No of deaths } & \multirow[t]{2}{*}{ Hazard ratio $(95 \% \mathrm{CI})$} & \multirow[t]{2}{*}{$p$ value } \\
\hline & Quit 1959-84 & $\begin{array}{l}\text { Continuous } \\
\text { smokers }\end{array}$ & & \\
\hline All cause & 181 & 462 & $0.71(0.50$ to 1.00$)$ & 0.049 \\
\hline Cardiovascular disease & 88 & 256 & $0.60(0.37$ to 0.98$)$ & 0.043 \\
\hline Cancer & 45 & 128 & $0.58(0.30$ to 1.12$)$ & 0.105 \\
\hline Lung cancer & 13 & 72 & $0.50(0.14$ to 1.77$)$ & 0.281 \\
\hline Other cancer & 32 & 56 & $0.62(0.28$ to 1.33$)$ & 0.220 \\
\hline Respiratory diseases $\dagger$ & 22 & 24 & $2.51(0.65$ to 9.70$)$ & 0.181 \\
\hline Other causes & 26 & 54 & $0.91(0.38$ to 2.18$)$ & 0.833 \\
\hline
\end{tabular}

${ }^{\star}$ From Cox's proportional, time dependent hazards regression model adjusted for age, baseline pulmonary function, baseline amount of smoking, body mass index, diastolic blood pressure, and total cholesterol. Continuous smokers as a reference group.

+ Number of deaths among those who quit and continuous smokers from COPD $=12$ and 10 , from pneumonia $=7$ and 11 , and from other causes $=3$ and 3 , respectively.
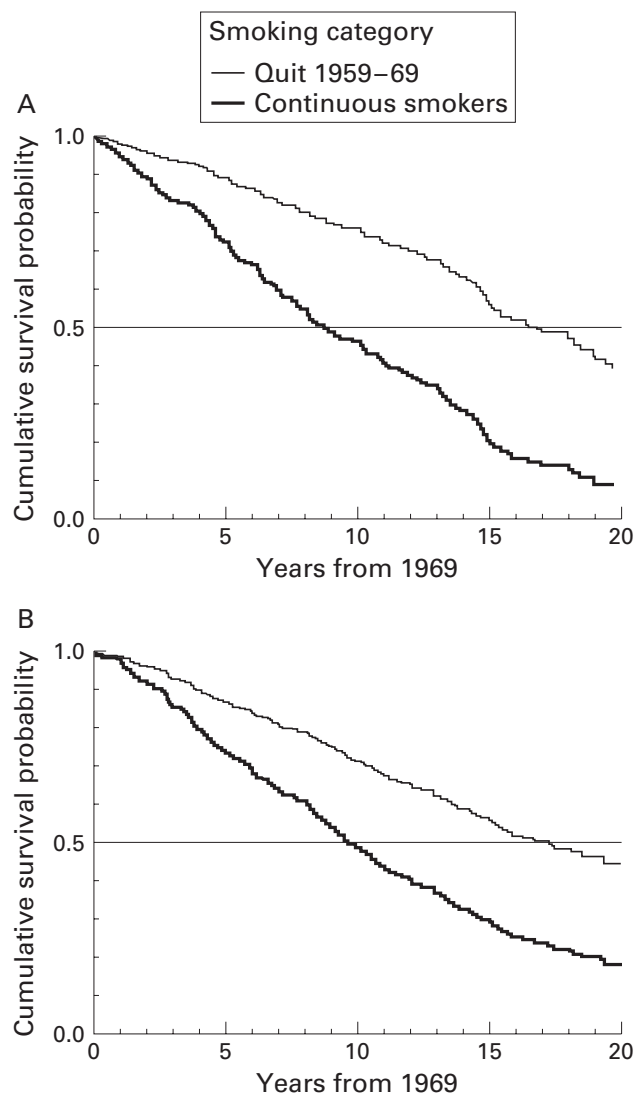

C

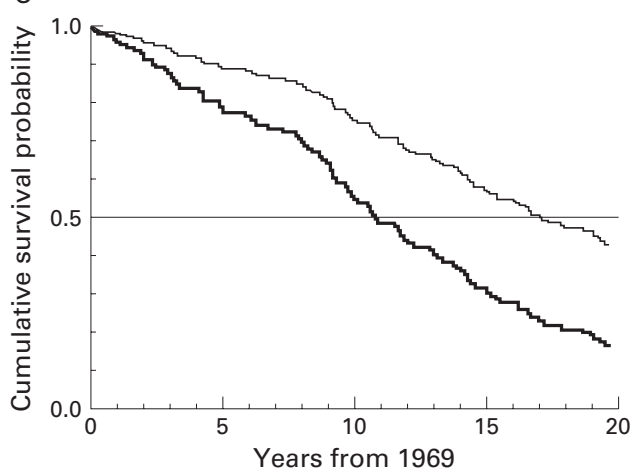

Figure 1 Cumulative survival probability curves for $(A)$ lowest, (B) middle, and (C) highest tertiles of FEV $V_{0.75}(\%$ predicted) at baseline in smokers based on Cox's proportional hazards regression model (adjusted for age, baseline amount of smoking, body mass index, diastolic blood pressure, and total cholesterol). smoking had significantly decreased mortality from cardiovascular disease (HR 0.60; 95\% CI 0.37 to 0.98 ). In addition, a positive interaction effect of borderline significance $(\mathrm{p}=0.066)$ was found between pulmonary function and smoking cessation on mortality from cardiovascular disease. In other words, the beneficial effect of smoking cessation on mortality from cardiovascular disease tended to be greater in study subjects with impaired pulmonary function. Among those who stopped smoking, mortality from many other causes except from respiratory diseases was also smaller but these results were not significant. In addition, a borderline negative interaction effect $(p=0.070)$ was found between pulmonary function and smoking cessation on mortality from lung cancer. Thus the beneficial effect of smoking cessation on mortality from lung cancer was smaller in men with impaired pulmonary function than in those with higher levels of pulmonary function.

The effect of smoking cessation on survival time at different levels of the entire range of $\mathrm{FEV}_{0.75}$ (\% predicted) is illustrated in fig 1. Median survival time is estimated by comparing mortality from all causes during 1969-89 in those who quit smoking during 1959-69 with mortality in those who continued to smoke. In all tertiles of $\mathrm{FEV}_{0.75}$ (\% predicted) those who gave up smoking had lower mortality and the median survival time, based on the Cox's proportional hazards regression model, was $7.65,7.59$, and 6.30 years longer, respectively, in the lowest, middle, and highest tertiles than for those who continued to smoke. When only those who quit smoking are selected, the survival curves in the lowest and middle tertiles of $\mathrm{FEV}_{0.75}$ (\% predicted) do not diverge significantly from the survival curve in the highest tertile of $\mathrm{FEV}_{0.75}$ (HR 0.88 (95\% CI 0.51 to 1.49 ) and 1.04 (95\% CI 0.61 to 1.76 ), respectively).

\section{Discussion}

This study has confirmed that impaired pulmonary function predicts increased long term mortality among middle aged men and provides evidence that giving up smoking has a beneficial effect on survival prospects over the entire range of pulmonary function. Our study population was a representative sample from the general male population in the two selected rural areas because the participation rate was very good both at the baseline $(97.5 \%$ in 1959) and in subsequent re-examinations (90$97.7 \%)$. The mortality data were also complete since all deaths between 1959 and 1989 were known. $\mathrm{FEV}_{0.75}$ was used as a measurement of obstruction and can be considered to measure approximately the same as $\mathrm{FEV}_{1}$ since $\mathrm{FEV}_{0.75}$ only needs to be multiplied by 1.09 to estimate the $\mathrm{FEV}_{1}{ }^{19}$

The hazards ratio for all cause mortality in the lowest tertile of age and height adjusted $\mathrm{FEV}_{0.75}$ distribution was 1.56 during 1959-89. This is consistent with the prospective population study in Renfrew and Paisley in which the hazard ratios for all cause mortality among men aged 45-64 years at baseline were 1.92 
and 1.51 in the first and second fifths of the adjusted $\mathrm{FEV}_{1}$ distribution, respectively. ${ }^{6} \mathrm{Haz}-$ ard ratios have been in the same direction in many other studies. ${ }^{4}$

Smoking is a well known risk factor for all cause mortality and for deaths from coronary heart disease..$^{21}$ Earlier studies have also shown that both total mortality and coronary heart disease mortality among former smokers have decreased after smoking cessation. ${ }^{22}{ }^{23} \mathrm{It}$ has been suggested that the effect of smoking on coronary heart disease is probably mediated through the role of smoking in the formation of atherosclerotic lesions ${ }^{24}$ and in the development of thrombosis. ${ }^{25}$ In this study those who gave up smoking had lower all cause mortality over the entire range of adjusted $\mathrm{FEV}_{0.75}$ distribution at the baseline, and the survival curves for these subjects in the three tertiles of $\mathrm{FEV}_{0.75}$ (\% predicted) were similar. The cause specific mortality analysis showed that those who stopped smoking had significantly decreased mortality from cardiovascular disease (consisting mainly of coronary deaths). In addition, a borderline significant interaction was found between pulmonary function and smoking cessation on mortality from cardiovascular disease. Those study subjects with impaired baseline pulmonary function therefore benefited especially from smoking cessation. This result is in agreement with the fact that impaired pulmonary function is significantly related to death from cardiovascular disease. ${ }^{4626}$ To explain the association between impairment of pulmonary function and increased mortality from cardiovascular disease, Tockman and Comstock have reported that airway obstruction caused by repeated inflammatory injury during ageing may lead to mild chronic hypoxia. ${ }^{1}$ This, in conjunction with reductions in cardiac output, may result in increased cardiovascular mortality. The type of inflammatory insult was not important. However, besides long term irreversible changes, a reversible inflammatory lesion has been described in smokers so that giving up smoking causes slight bronchodilation. ${ }^{11} 122728$

Our results concerning the beneficial effect of smoking cessation on mortality from cardiovascular disease are perhaps mainly explained by the atherosclerotic and thrombotic mechanisms. Among those who gave up smoking with a baseline $\mathrm{FEV}_{0.75}$ (\% predicted) in the lowest tertile of pulmonary function, the additional beneficial effect could have been achieved by a decrease in the rate of decline in pulmonary function. Perhaps these men in the lowest tertile of baseline $\mathrm{FEV}_{0.75}$ were more susceptible to inflammation caused by smoking and thus benefited especially from the bronchodilatation on quitting. The idea of susceptible smokers has already been put forward by Fletcher et al when they noticed that smoking in susceptible subjects was associated with a steeper decline in pulmonary function. ${ }^{13}$

Our data set was too small for confident results on mortality from causes other than cardiovascular diseases. However, the results were consistent with earlier findings in these rarer causes of death. For example, those who stopped smoking had lower mortality from lung cancer as well as from other cancers. ${ }^{20} 2930$ Mortality from respiratory diseases was higher among those who gave up smoking, mainly because these individuals gave up smoking too late and thus died from severe COPD.

In conclusion, our study provides evidence that smoking cessation can improve the survival prospects of middle aged smokers over the entire range of pulmonary function. However, since our data came from an observational study, some caution is required in causal inferences based on the results. As in any observational study, it is possible that some confounding factors may, at least partly, explain the findings. For example, it is possible that those men who gave up smoking adopted a generally more healthy lifestyle, and thus changes other than smoking cessation might have contributed to the increase in their life expectancy.

Supported by grants from the Finnish Academy, the Finnish Lung Health Association, the Finnish Anti-Tuberculosis Association Foundation, and the National Institute on Aging, USA (grant EDC-1 1 RO1 AGO8762-01A1).

1 Tockman MS, Comstock GW. Respiratory risk factors and mortality: longitudinal studies in Washington County, mortality: longitudinal studies in Washington

2 Beauty TH, Newill CA, Cohen BH, et al. Effects of pulmoBeauty TH, Newill CA, Cohen BH, et al. Effects of pulmo-
nary function on mortality. F Chronic Dis 1985;28:703-10. nary function on mortality. F Chronic Dis 1985;28:703-10.
Sorlie PD, Kannel WB, O'Connor G. Mortality associated with respiratory function and symptoms in advanced age. Am Rev Respir Dis 1989;140:379-84.

4 Kryzanowski M, Wysocki M. The relation of thirteen year mortality to ventilatory impairment and other respiratory symptoms: The Cracow study. Int $\mathcal{F}$ Epidemiol 1986;15:5664.

5 Lange $\mathrm{P}$, Nyboe J, Appleyard M, et al. Spirometric findings and mortality in never-smokers. F Clin Epidemiol 1990;43: 867-73.

6 Hole DJ, Watt GCM, Davey-Smith G, et al. Impaired lung function and mortality risk in men and women: findings from the Renfrew and Paisley prospective population study. BMF 1996;313:711-5.

7 Ashley F, Kannel WB, Sorlie PD, et al. Pulmonary function: relation to aging, cigarette habit and mortality. The Framrelation to aging, cigarette habit and mortality. The
ingham Study. Ann Intern Med 1975;82:739-45.

8 Ebi-Kriston K. Respiratory symptoms and pulmonary funcEbi-Kriston $\mathrm{K}$. Respiratory symptoms and pulmonary func-
tion as predictors of 10 -year mortality from respiratory disease, cardiovascular disease, and all causes in the Whitehall Study. F Clin Epidemiol 1988;41:251-60.

9 Bang KM, Gergen P J, Kramer R, et al. The effect of pulmonary impairment on all-cause mortality in a national cohort. Chest 1993;103:536-40.

10 Burchfiel CM, Marcus EB, Curb JD, et al. Effects of smoking and smoking cessation on longitudinal decline in pulmonary function. Am F Respir Crit Care Med 1995;151: 1778-85.

$11 \mathrm{Xu}$ X, Dockery DW, Ware JH, et al. Effects of cigarette smoking on rate of loss of pulmonary function in adults: a longitudinal assessment. Am Rev Respir Dis 1992;146: 1345-8.

12 Camilli AE, Burrows B, Knudson RJ, et al. Longitudinal changes in forced expiratory volume in one second in adults. Effects of smoking and smoking cessation. Am Rev Respir Dis 1987;135:794-9.

13 Fletcher C, Peto R. The natural history of chronic airflow obstruction. BMF 1977;1:1645-8.

14 Karvonen M, Blomqvist G, Kallio V, et al. Men in rural east and west Finland. Acta Med Scand 1967;460:169-90.

15 Keys A. Coronary heart disease in seven countries. American Heart Association Monograph, 1970.

16 Menotti A, Keys A, Blackburn H, et al. Twenty-year stroke mortality and prediction in twelve cohorts of the Seven Countries Study. Int $\mathcal{F}$ Epidemiol 1990;19:309-15.

17 Rose GA, Blackburn H. Cardiovascular survey method. Geneva: World Health Organization Monograph Series, 1968.

18 Altman DG. Practical statistics for medical research. 1st ed. Cornwall: Chapman \& Hall, 1991.

19 Cotes J E. Lung function: assessment and application in medicine. 3rd ed. Boston: Blackwell Scientific Publications, 1975 .

20 Jacobs DR Jr, Adachi H, Mulder I, et al. Cigarette smoking and mortality risk. Twenty-five-year follow-up of the Seven Countries Study. Arch Intern Med 1999;159:733-40. 
21 Menotti A, Keys A, Blackburn H, et al. Comparison of multivariate predictive power of major risk factors for coronary heart diseases in different countries: results from eight nations of the Seven Countries Study, 25-year follow-up. $\mathcal{F}$ Cardiovasc Risk 1996;3:69-75.

22 Tverdal A, Thelle D, Stensvold I, et al. Mortality in relation to smoking history: 13 years' follow-up of 68,000 Norwegian men and women $35-49$ years. $\mathcal{F}$ Clin Epidemiol 1993;46:475-87.

23 Kawachi I, Colditz GA, Stampfer MJ, et al. Smoking cessation in relation to total mortality rates in women. A prospective cohort study. Ann Intern Med 1993;119:9921000 .

24 Waters D, Lesperance J, Gladstone P, et al. Effects of cigarette smoking on the angiographic evolution of coronary atherosclerosis. A Canadian Coronary Atherosclerosis Intervention Trial (CCAIT) Substudy. CCAIT Study Group. Circulation 1996;94:614-21.
25 Hamsten A. The hemostatic system and coronary heart disease. Thromb Res 1993;70:1-38.

26 Ebi-Kriston KL, Hawthorne VM, Rose G, et al. Breathlessness, chronic bronchitis and reduced pulmonary function as predictors of cardiovascular disease mortality among men in England, Scotland and the United States. Int $\mathcal{F}$ Epidemiol 1989;18:84-8.

27 Muers MF. Quitting smoking and lungs. Lancet 1999;354: $177-8$.

28 Murray RP, Anthonisen NR, Connett JE. Effects of multiple attemps to quit smoking and relapses to smoking on pulmonary function. F Clin Epidemiol 1998;51:317-26.

29 Peto R, Lopez AD, Boreham J, et al. Mortality from tobacco in developed countries: indirect estimation from national vital statistics. Lancet 1992;339:1268-78.

30 Doll R, Peto R, Wheatley K, et al. Mortality in relation to smoking: 40 years' observations on male British doctors. BMf 1994;309:901-11. 